University of Nebraska - Lincoln

DigitalCommons@University of Nebraska - Lincoln

Virology Papers

Virology, Nebraska Center for

2009

\title{
Characterization of a monothiol glutaredoxin encoded by Chlorella virus PBCV-1
}

\author{
Lisa A. Fitzgerald \\ University of Nebraska-Lincoln, lisa.fitzgerald@nrl.navy.mil \\ Yuanzheng Zhang \\ University of Nebraska-Lincoln \\ Gentry L. Lewis \\ University of Nebraska-Lincoln, glewis2@unl.edu \\ James L. Van Etten \\ University of Nebraska-Lincoln, jvanetten1@unl.edu
}

Follow this and additional works at: https://digitalcommons.unl.edu/virologypub

Part of the Virology Commons

Fitzgerald, Lisa A.; Zhang, Yuanzheng; Lewis, Gentry L.; and Van Etten, James L., "Characterization of a monothiol glutaredoxin encoded by Chlorella virus PBCV-1" (2009). Virology Papers. 195.

https://digitalcommons.unl.edu/virologypub/195

This Article is brought to you for free and open access by the Virology, Nebraska Center for at DigitalCommons@University of Nebraska - Lincoln. It has been accepted for inclusion in Virology Papers by an authorized administrator of DigitalCommons@University of Nebraska - Lincoln. 
Published in Virus Genes 39 (2009), pp. 418-426; doi: 10.1007/s11262-009-0392-8 Copyright @ 2009 Springer Science+Business Media, LLC. Used by permission.

Submitted April 8, 2009; accepted August 5, 2009; published online August 21, 2009

\title{
Characterization of a monothiol glutaredoxin encoded by Chlorella virus PBCV-1
}

\author{
Lisa A. Fitzgerald, ${ }^{1}$ Yuanzheng Zhang, ${ }^{1}$ Gentry Lewis, ${ }^{2,3}$ and James L. Van Etten ${ }^{1,3}$ \\ 1 Department of Plant Pathology, University of Nebraska, Lincoln, NE 68583, USA \\ 2 School of Biological Sciences, University of Nebraska, Lincoln, NE 68588, USA \\ 3 Nebraska Center for Virology, University of Nebraska, Lincoln, NE 68583-0900, USA \\ Present address for L. Fitzgerald - Chemistry Division, U.S. Naval Research Laboratory, Washington, DC 20375, USA \\ Present address for Y. Zhang - Schering-Plough Animal Health, Elkhorn, NE 68022, USA
}

Corresponding author - James L. Van Etten, e-mail jvanetten@unlnotes.unl.edu

\begin{abstract}
Annotation of the 330-kb Chlorella virus PBCV-1 genome identified a 237 nucleotide gene (a438l) that codes for a protein with $\sim 35 \%$ amino acid identity to glutaredoxins (Grx) found in other organisms. The PBCV1 protein resembles classical Grxs in both size $(9 \mathrm{kDa})$ and location of the active site (N-terminus). However, the PBCV-1 Grx is unusual because it contains a monothiol active site (CPYS) rather than the typical dithiol active site (CPYC). To examine this unique active site, four site-specific mutants (CPYC, CPYA, SPYC, and SPYS) were constructed to determine if the N-terminal cysteine is necessary for enzyme activity. Wild type and both mutants containing $\mathrm{N}$-terminal cysteines catalyzed the reduction of disulfides in a coupled system with GSH, $\mathrm{NADPH}$, and glutathione reductase. However, both mutants with an altered $\mathrm{N}$-terminal cysteine were inactive. The grx gene is common in the Chlorella viruses. Molecular phylogenetic analyses of the PBCV-1 enzyme support its relatedness to those from other Chlorella viruses and yet demonstrate the divergence of the Grx molecule.
\end{abstract}

Keywords: Chlorella viruses, Phycodnaviridae, Virus PBCV-1, Monothiol glutaredoxin, Classical glutaredoxin

\section{Introduction}

Glutaredoxins (Grxs) are a major source of reducing power in almost all living cells. They participate in a variety of cellular functions, such as providing reducing equivalents for ribonucleotide reductase, antioxidant defense, control of cellular redox state, and the redox control of transcription and signal transduction (for recent reviews on Grxs see Refs. [1-3]). To perform redox reactions, Grxs have evolved two catalytic mechanisms $[3,4]$. The dithiol mechanism uses the two adjacent Cys residues in the active site (usually CPYC) to reduce protein-S-S or protein-S-S-glutathione substrates $[5,6]$. The alternative monothiol mechanism (usually active site CGFS) can only reduce protein-S-S-glutathione substrates $[\mathbf{1}, \mathbf{5}]$.

There are four classes of Grxs based on their structure and catalytic mechanism [4, 7-11]. Members of the first class, commonly referred to as classical Grxs, are 9$12 \mathrm{kDa}$ in size. Members of the second class, e.g., present in Escherichia coli, are twice the size of the classical Grx $(24.3 \mathrm{kDa})$ [12]. Both of these classes have a dithiol active site that is typically a CPYC sequence located near the $\mathrm{N}$-terminus $[13,14]$. Members in the third class contain a monothiol active CGFS site that is located in the cen- 
tral portion of a 9-12 kDa protein [13]. More recently, a fourth class of Grxs has been described in higher plants. This class is referred to as CC due to the active sites consisting of either CCXC or CCXS [9-11].

Annotation of the 330-kb dsDNA genome of Chlorella virus PBCV-1, the prototype virus of the genus Chlorovirus (family Phycodnaviridae), revealed an open reading frame (ORF) encoding a putative Grx [15]. This virus-encoded Grx is similar to classical Grxs with its 9$\mathrm{kDa}$ size and the location of its active site in the N-terminus. However, the active site is unusual because it contains a monothiol (CPYS) rather than the typical dithiol. Herein, we demonstrate that the PBCV-1 encoded protein has Grx activity. We also determined that the active site must have a CXXX motif in the active site to be functional.

\section{Materials and methods}

Strains and culture conditions

Viral hosts Chlorella NC64A and Chlorella Pbi, were grown on MBBM and FES media, respectively. The growth of the host, production and purification of the viruses, and the isolation of virus DNAs have been described $[16,17]$. E. coli strains DH5aMCR (E. coli Genetic Stock Center, New Haven, CT) and BL21(DE3)pLysS (Novagen, Madison, WI) were grown in Luria-Bertani (LB) medium [18].

\section{Cloning and expression of PBCV-1 Grx}

PBCV-1 gene 94381 was cloned from viral DNA amplified by PCR with the following oligonucleotide primers:

\section{5'Primer:GGTGGTCATATGTCGTTTAAATTATTTGTG}

\section{3' Primer: CCGCTCGAGTTTTCTTAAATGTTTCAC}

The NdeI and XhoI endonuclease recognition sites used for cloning are underlined. The $a 4381$ gene was amplified with KOD hot start DNA Polymerase (Novagen) in $50 \mu \mathrm{l}$ reactions containing $100 \mathrm{ng}$ of virus DNA, $15 \mathrm{pM}$ of each primer, $0.2 \mathrm{mM}$ each of dATP, dGTP, dCTP, dTTP and $1 \mathrm{mM} \mathrm{MgSO}$ by 35 cycles of heating and cooling: $15 \mathrm{~s}$ at $94^{\circ} \mathrm{C}$ for denaturing, $30 \mathrm{~s}$ at $60^{\circ} \mathrm{C}$ for annealing, $1 \mathrm{~min}$ at $68^{\circ} \mathrm{C}$ for elongation. The PCR products were purified from 1.2\% agarose gels using a QIAEX II Gel Extraction kit (QIAGEN, Valencia, CA), digested with NdeI and XhoI, and inserted into the NdeI/XhoI sites of the pET23a+ expression vector (Novagen). This resulted in the addition of a 6-His residue tag at the C-terminus of the target protein.
The construction of the recombinant expression plasmid, named pETA438L, was confirmed by DNA sequencing. Plasmid, pETA438L, was transformed into either E. coli strain DH5aMCR (for maintenance) or BL21(DE3)pLysS (for expression).

The Grx protein was expressed in E. coli BL21(DE3)/ pLysS, which contains the T7 RNA polymerase gene under control of the isopropyl- $\beta$-D-thiogalactopyranoside (IPTG) inducible lacUV5 promoter, and a plasmid constitutively expressing T7 lysozyme, an inhibitor of T7 RNA polymerase. Transformed cells were grown overnight in LB medium at $37^{\circ} \mathrm{C}$. Flasks containing $400 \mathrm{ml} \mathrm{LB}$ medium, which contain $100 \mu \mathrm{g} / \mathrm{ml}$ ampicillin and $37 \mu \mathrm{g} / \mathrm{ml}$ chloramphenicol, were inoculated with $1 / 40$ volume of the overnight culture, and incubated at $37^{\circ} \mathrm{C}$ until the absorbance at $595 \mathrm{~nm}$ reached 0.6-0.8. IPTG (Sigma, St. Louis, MO) was added to a final concentration of $0.5 \mathrm{mM}$, and incubation was continued for $2 \mathrm{~h}$ at $30^{\circ} \mathrm{C}$. One liter of cells was harvested by centrifugation at $5,000 \times g$ for $5 \mathrm{~min}$ and resuspended in $50 \mathrm{ml}$ NPI-10 buffer ( $50 \mathrm{mM}$ phosphate buffer, $\mathrm{pH}$ 8.0; $300 \mathrm{mM} \mathrm{NaCl} ; 10 \mathrm{mM}$ imidazole). The cells were disrupted on ice by sonication for $4 \mathrm{~min}$ using a Tekmar sonic disruptor at $100 \%$ amplitude, in $5 \mathrm{~s}$ pulses. The sonicated samples were centrifuged at $12,000 \times g$ for $10 \mathrm{~min}$ to separate soluble and insoluble fractions. Ni-NTA agarose beads (Qiagen, Hilden, Germany) equilibrated with NPI-10 buffer were added to the soluble fraction. After mixing for $1 \mathrm{~h}$ at $4^{\circ} \mathrm{C}$, the resin was loaded in a column and washed with 20 column volumes of NPI-20 buffer $(50 \mathrm{mM}$ phosphate buffer, pH 8.0, $300 \mathrm{mM} \mathrm{NaCl}, 20 \mathrm{mM}$ imidazole). Recombinant Grx protein was eluted from the column by NPI-250 buffer ( $50 \mathrm{mM}$ phosphate buffer, $\mathrm{pH}$ 8.0, $300 \mathrm{mM} \mathrm{NaCl}, 250 \mathrm{mM}$ imidazole). Fractions containing the recombinant proteins were pooled, and protein concentrations were determined using the Lowry et al. method [19]. Glycerol was added to the sample until the final concentration was $50 \%$, and stored at $-20^{\circ} \mathrm{C}$.

\section{Cloning and expression of mutant PBCV-1 Grxs}

Three Grx mutants were constructed using 5' primers containing a single amino acid change within the active site located 11-14 amino acids from the N-terminus. In addition to the three single point mutants, a mutant was created which contained two mutations in the active site. The first mutant created a classical Grx by altering the wild type active site (CPYS) to the typical dithiol active site (CPYC). This was achieved by using the following $5^{\prime}$ primer that incorporated both the NdeI site (for cloning) and the serine to cysteine mutation within the active site. 


\section{Wildtype (WT) 5' Primer : GGTGGTCATATGTCGTTTAAATTATTTGTG \\ + CGC CCG GGA TGT CCC TAT $\underline{T G T}$ ACG \\ $\begin{array}{llllllll}R & P & G & \text { C } & \mathbf{P} & \mathbf{Y} & \underline{\mathbf{C}} & \mathrm{T}\end{array}$}

The changed codon is underlined and italicized and the nucleotide change is in bold. Below the primer sequence is the corresponding amino acid sequence with the active site indicated in bold and the point mutation underlined. In the second mutant, the wild type active site (CPYS) was mutated to CPYA using the following 5' primer:

$$
\begin{aligned}
& 5^{\prime} \text { Primer (WT } 5^{\prime} \text { primer) +CGC CCG GGA TGT CCC TAT } \underline{G C T} \text { ACG } \\
& \begin{array}{lllllllll}
\mathrm{R} & \mathrm{P} & \mathrm{G} & \mathbf{C} & \mathbf{P} & \mathbf{Y} & \underline{\mathbf{A}} & \mathrm{T}
\end{array}
\end{aligned}
$$

The third construction mutated the N-termini cysteine to a serine by using the following 5 ' primer:

$$
\begin{aligned}
& 5^{\prime} \text { Primer (WT } 5^{\prime} \text { primer) + CGC CCG GGA } \underline{T C T} \text { CCC TAT TCT ACG } \\
& \begin{array}{llllllll}
\mathrm{R} & \mathrm{P} & \mathrm{G} & \underline{\mathbf{S}} & \mathbf{P} & \mathbf{Y} & \mathbf{S} & \mathrm{T}
\end{array}
\end{aligned}
$$

The fourth construction switched the N-terminal cysteine with the C-terminal serine, resulting in a CPYS to SPYC change, using the following primer:

$$
\begin{aligned}
& \text { 5'Primer(WT 5'primer) + CGCCCGGGATCT CCC TAT } \underline{T G T} \text { ACG } \\
& \begin{array}{llllllll}
\mathrm{R} & \mathrm{P} & \mathrm{G} & \underline{\mathbf{S}} & \mathbf{P} & \mathbf{Y} & \underline{\mathbf{C}} & \mathrm{T}
\end{array}
\end{aligned}
$$

Expression and purification of the mutant Grxs were carried out as described for wild type Grx.

\section{Enzyme assays}

Grx activity was determined by the assay developed by Mieyal et al. [20, 21] as modified by Raghavachari and Lou [22]. Unless otherwise noted, the reaction mixtures contained $0.2 \mathrm{mM}$ NADPH, $0.5 \mathrm{mM} \mathrm{GSH}, 0.1 \mathrm{M}$ Tris ( $\mathrm{pH}$ 8.5), 0.4 units of GSSG reductase, and an aliquot of purified Grx in a total volume of $1 \mathrm{ml}$. The reaction was incubated at $37^{\circ} \mathrm{C}$ after a 5 min pre-incubation with $2 \mathrm{mM}$ synthetic substrate, hydroxyethyldisulfide (HEDS). The decrease in absorbance of NADPH at $340 \mathrm{~nm}$ was monitored for 5 min using a Beckman DU 640 Spectrophotometer (Beckman, Fullerton, CA). To determine Grx activity, the slope of the linear portion of the time course for 340-nm absorption loss in a control (Grx-free) sample was subtracted from the slope of the experimental (Grx-containing) samples. One unit of Grx activity was defined as the amount of enzyme required to oxidize $1 \mu \mathrm{mol}$ of NADPH per min under these standard assay conditions. 
Determination of optimal $\mathrm{pH}$ and temperature

The optimal $\mathrm{pH}$ for Grx activity was determined by performing the standard assays (described above) at $25^{\circ} \mathrm{C}$ with a $10 \mathrm{mM}$ mixture in each of the following buffers: (1) Pipes $\left(\mathrm{pK}_{\mathrm{a}} 6.8\right.$; range 6.1-7.5), (2) Hepes $\left(\mathrm{pK}_{\mathrm{a}}\right.$ 7.5; range 6.8-8.2), (3) Tris ( $\mathrm{pK}_{\mathrm{a}} 8.1$; range 7-9), and (4) Capso $\left(\mathrm{pK}_{\mathrm{a}}\right.$ 9.6; range 8.9-10.3). The optimal temperature for Grx activity was determined in Tris buffer $(\mathrm{pH}$ 8.5) in a Beckman DU 640 Spectrophotometer with a Peltier temperature control module.

\section{Dot blot analyses}

Viral DNA used for dot blots was denatured and transferred to nylon membranes (Micron Separations Inc., Westborough, MA) as previously described [23]. DNA was hybridized to an antisense ${ }^{32} \mathrm{P}$-single-stranded full length $g r x$ probe (the $g r x$ probe was made using Invitrogen Random Primers DNA Labeling System) at $65^{\circ} \mathrm{C}$ in $50 \mathrm{mM} \mathrm{NaPO}{ }_{4}, 1 \% \mathrm{BSA}$, and 2\% SDS. After hybridization, radioactivity bound to the membrane was detected using a Storm 840 Phosphorimager and ImageQuant software (Molecular Dynamics, Inc., Sunnyvale, CA).

\section{Phylogenetic analyses}

A BLASTP search with the amino acid sequence of PBCV-1 A438L (AAC96806) was conducted using the NCBI non-redundant protein sequences database with default settings. An unrooted Bayesian inference, Markov chain Monte Carlo (MCMC), posterior probability tree, of 40 Grx protein sequences was generated based on sequence alignment using ClustalX-2.0.10 and Mr. Bayes within the Geneious Pro 4.5.4 software program [24]. The Poisson (fixed) amino acid gamma rate variation of four categories was used. MCMC settings of $1,100,000$ chain length, four heated chains at a temperature setting of 0.2 and a sub-sampling of 200 with the burn in length of 100,000 analyzed 4,951 samples and produced the illustrated tree and clade support (clade support values of less than 0.50 are not displayed). MUSCLE alignments, Neighbor-Joining (Geneious Tree Builder, Jukes-Cantor Model and Maximum Likelihood (PHYML, Jones-Taylor-Thornton Model) phylogenies were carried out as well (data not shown) [24].

\section{Other procedures}

DNA and protein sequences were analyzed using the Genetics Computer Group (GCG) Wisconsin Package, v. 10.3 [25]. Alignment and shading of conserved nucleotides were created using Boxshade. The GenBank Accession Number for the PBCV-1 genome is U42580. The PBCV-1 ORF A438L GeneID number is 918084 and the protein number is AAC96806.

\section{Results}

PBCV-1 ORF A438L resembles a Grx

Database searches using the predicted 365 PBCV-1 protein-encoding genes identified an ORF (A438L) with $\sim 35 \%$ amino acid identity with Grxs from prokaryotic and eukaryotic organisms. Amino acid alignment of A438L with Grxs from three eukaryotic and three prokaryotic organisms reveals that PBCV-1 Grx is most similar to classical Grxs (Figure 1). This similarity is evident in its size, the PBCV-1 Grx is $9 \mathrm{kDa}$ and classical Grxs are typically 9-12 kDa. The second similarity is in the location of the enzymes' active site, which occurs in the N-terminal portion of the protein. However, one major difference between PBCV-1 Grx and other classical Grxs is the presence of a monothiol (CPYS) active site instead of the typical dithiol (CPYC) active site found in most classical Grx enzymes. The G+C content of the amino acid coding portion of the $a 4381$ gene is $40 \%$, a value identical to the entire PBCV-1 genome [26]. The 50 nucleotides upstream of the A438L ATG start codon, which could serve as the a438l transcriptional start site, is $88 \% \mathrm{~A}+\mathrm{T}$.

Expression and purification of recombinant PBCV-1 Grx

To determine if $a 4381$ encodes a functional Grx, a plasmid, pETA438L, was constructed to express a His-tagged recombinant enzyme in E. coli. Cells containing pETA438L produced the expected 9-kDa recombinant fusion protein after induction with IPTG. About 70\% of the His-A438L protein is in the soluble fraction of the bacterial extracts. The protein was purified to apparent homogeneity over a Ni-NTA column. Approximately $0.5 \mathrm{mg}$ of recombinant protein was obtained per liter of $E$. coli cells.

Characterization of wild type and mutant PBCV-1 recombinant Grxs

Characterization of the wild type and four mutant PBCV-1 Grx enzymes revealed that recombinant proteins, which contained a cysteine in the $\mathrm{N}$-terminal position of the active site, were functionally active. The two mutants containing an $\mathrm{N}$-terminal serine had no detect- 
PBCV-1_GRX

B. tribocorum

B. canis

o. anthropi

X. laevis

H. sapiens

E.caballus
1

1 作 - - - - - MVDVT I Y TRVGCPYCTRARDILTR---KGVAYNEIDAGASPEIRAEMOQ MAQNFVQSKVKPSKUTTMEKS SCPFCVRARG ITTKYKFEEGHLEIIDISKL-DFMS SLOQ MAQEFVNCKIQPGKLVVGIKPTCPYCRRAQEINSQLSTEZQRLEFVDITAS-NHTNKIDD

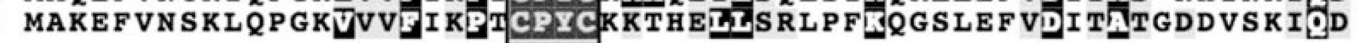

PBCV-1_GRX

B. tribocorum

B. canis

o. anthropi

X. laevis

H. sapiens

E. caballus

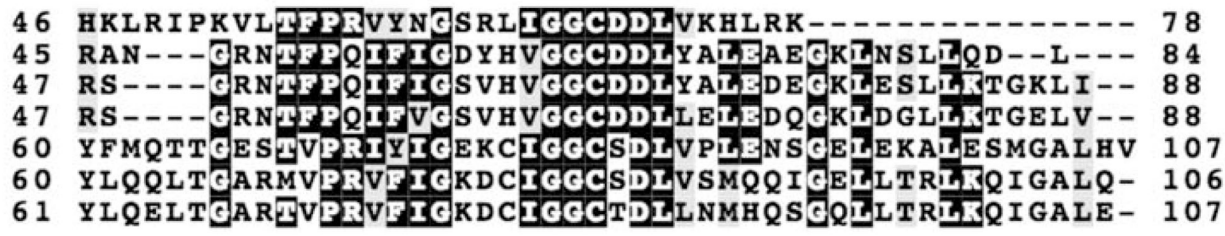

Figure 1. Multiple amino acid sequence alignments to PBCV-1 Grx. Amino acid alignment of Grxs coded by PBCV-1, three prokaryotic organisms (Bartonella tribocorum CIP 105476 [YP_001609045.1], Brucella canis ATCC 23365 [YP_001593681.1] and Ochrobactrum anthropi ATCC 49188 [YP_001369579.1]) and three eukaryotic organisms (Xenopus laevis [NP_001083654.1], Homo sapiens [NP_ 001116860.1] and Equus caballus [XP_001504659.1]). The gray box indicates the glutaredoxin active site.

able enzyme activity. The three active enzymes had temperature optima of $37^{\circ} \mathrm{C}$ (Figure 2) and $\mathrm{pH}$ optima of 8.5 (Figure 3). All three enzymes retained significant activity from 25 to $42^{\circ} \mathrm{C}$ and at pHs of $6.5-10.0$.

The $\mathrm{Km}$ for HEDS was 2.1, 3.9, and $1.4 \mathrm{mM}$ for CPYS, CPYC, and CPYA active site-containing enzymes, respectively (Table 1). A minimal difference in
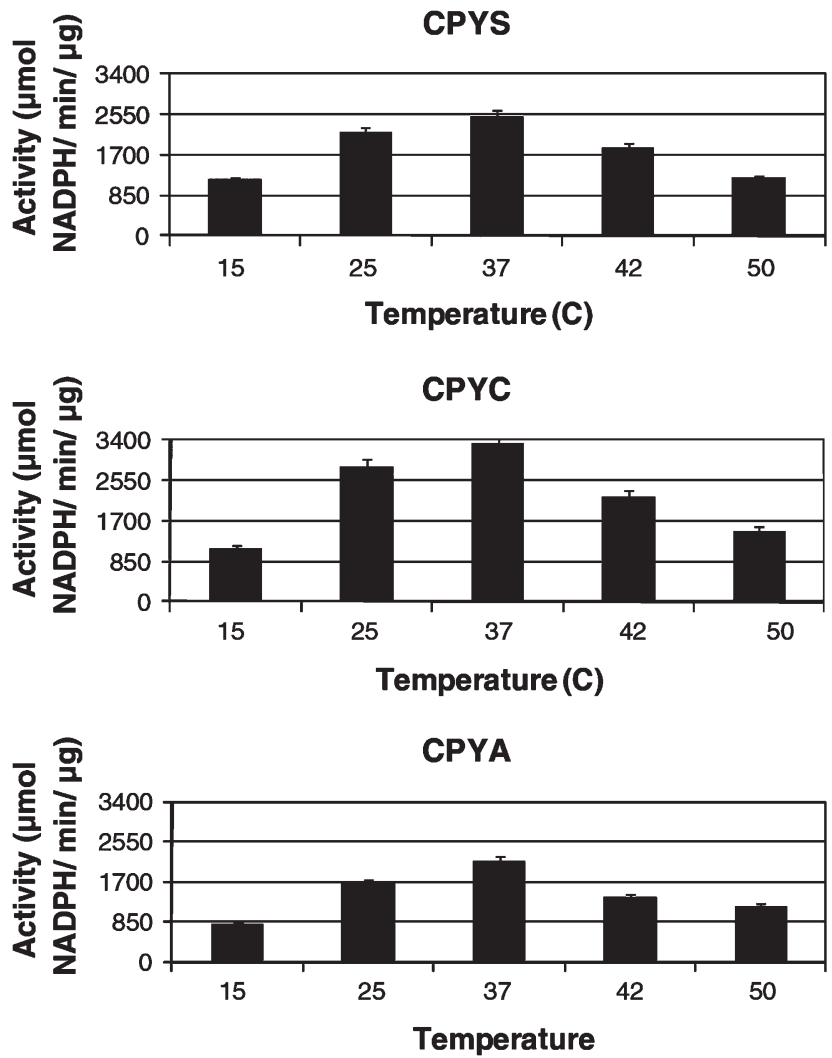

Figure 2. Effect of temperature on PBCV-1 GRX wild type and site-specific mutants. All assays were run in triplicate with the same preparation of enzyme. Shown are the averages with 5\% error bars. specific activity, 3.1-4.2 U/mg occurred between the wild type Grx and the two active mutants. The largest kinetic difference occurred in the $V$ max $_{\text {in which }}$ the CPYA active site was 4.5 , the wild type CPYS active site was 5.9, and the CPYC active site was 10.9 (Table 1). PBCV-1 Grx does not require any metals for activity.
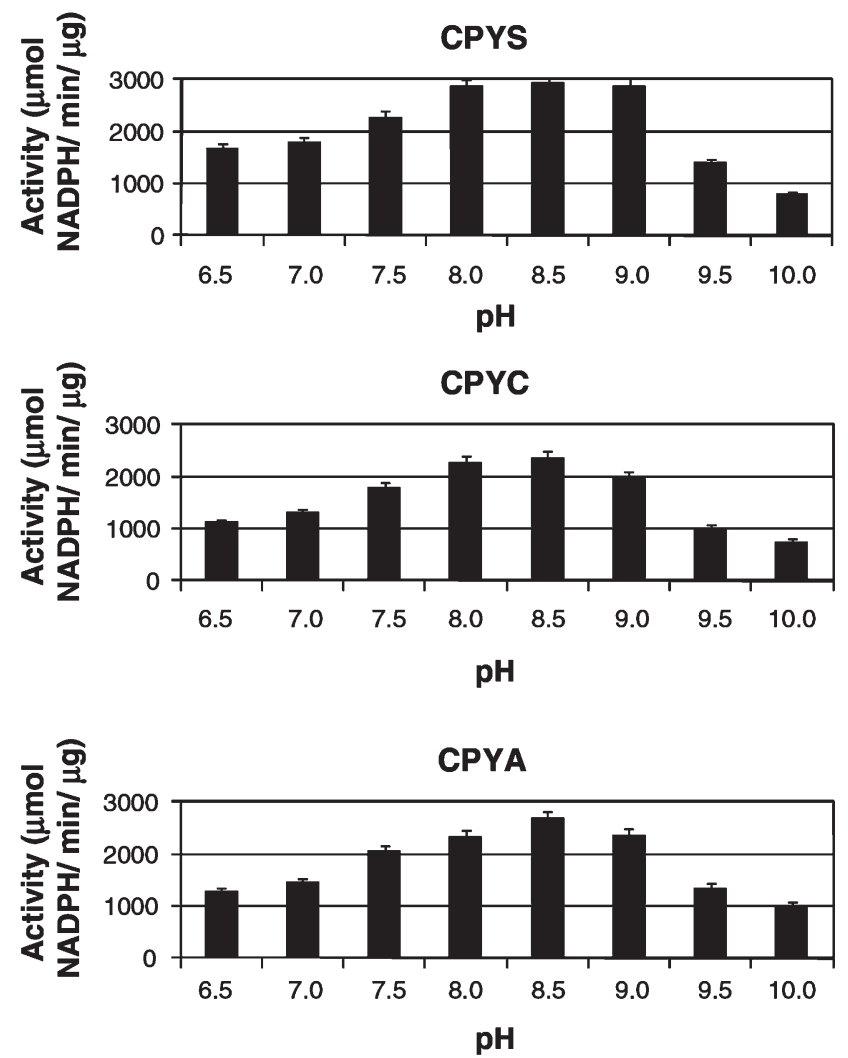

Figure 3. Effect of pH on PBCV-1 GRX wild type and site-specific mutants. All assays were run in triplicate with the same preparation of enzyme. Shown are the averages with 5\% error bars. 
Table 1. Kinetics of PBCV-1 Grx and four mutants

\begin{tabular}{llll}
\hline & $\mathrm{km}(\mathrm{mM})$ & $V_{\max }$ & Specific activity $(\mathrm{U} / \mathrm{mg})$ \\
\hline WT (CPYS) & 2.1 & 5.9 & 3.4 \\
CPYC & 3.9 & 10.9 & 4.2 \\
CPYA & 1.4 & 4.5 & 3.1 \\
SPYC & No activity & & \\
SPYS & No activity & \\
\hline
\end{tabular}

Data was obtained from Lineweaver-Burk plots using five different substrate concentrations $(0.33,0.67,1.00,1.33$, and $2.00 \mathrm{mM}$ HEDS). The $R^{2}$ values for the plots were 0.99 in each case.

Presence of $a 4381$ genes in other Chlorella viruses

To determine if the $a 4381$ gene is common among the Chlorella viruses, genomic DNA from 47 Chlorella viruses isolated from diverse geographical regions were hybridized to an antisense ${ }^{32} \mathrm{P}$-single-stranded $g r x$ probe. DNA from 32 of the viruses that infect Chlorella NC64A hybridized strongly with the probe; weak or no hybridization occurred with 10 viruses that infect the same host (NC64A viruses) (Figure 4). No hybridization was detected with DNA from the Chlorella NC64A host or with DNA from four of the five viruses which infect Chlorella Pbi (Pbi viruses). These results indicate that $g r x$ genes are common among the Chlorella viruses. However, the lack of hybridization to some of the viruses may reflect either an absence of the gene in some of the viruses or, more likely, a substantially diverged gene that does not hybridize to the probe.

Annotation of five additional, recently sequenced, Chlorella virus genomes revealed eight putative Grx [27-29]. Two of these sequenced viruses, NY-2A and AR158, are NC64A viruses and did not hybridize with the PBCV-1 probe. All three NC64A viruses encode a single Grx with a monothiol active site. However, the active sites for NY-2A and AR158 (CSYS) differ from PBCV-1's active site (CPYS). Viruses MT325 and FR483 are $\mathrm{Pbi}$ viruses and both viruses encode two dithiol Grxs with two different active sites, CRYC and CPHC. Finally, virus ATCV-1, which infects Chlorella SAG 3.83, encodes two Grxs. One Grx has the same active site found in one of the Pbi virus Grxs (CPHC) and the other Grx has a CKYC active site (Figure 5).

Phylogenetic analysis

BLASTP analysis using the non-redundant amino acid NCBI database indicated the PBCV-1 Grx had the greatest degree of sequence similarity to Grx enzymes present in cyanobacteria and pathogenic Gram negative bacteria (Figure 1). A Bayesian inference posterior

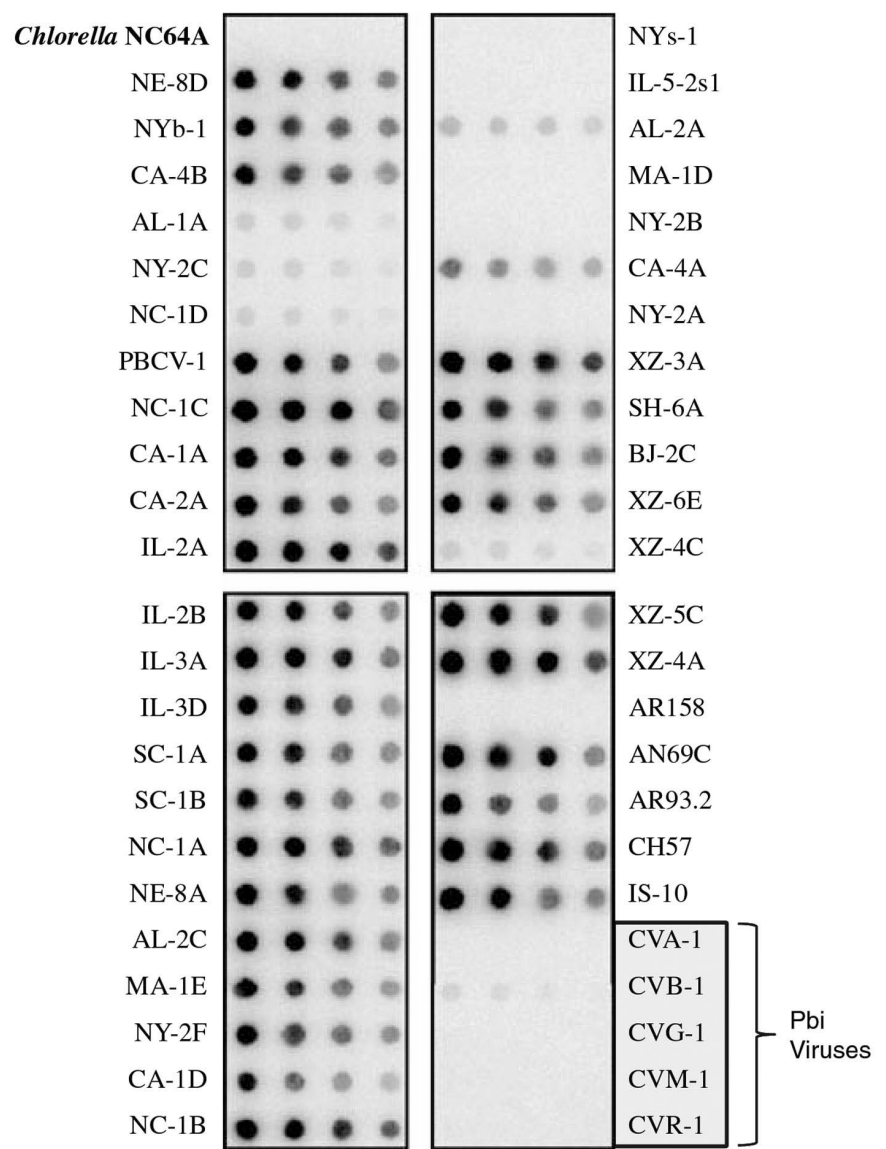

Figure 4. Occurrence of the PBCV-1 grx gene in other Chlorella viruses. Hybridization of the PBCV-1 a438l gene to DNAs isolated from the host Chlorella NC64A and 42 viruses that infect Chlorella NC64A and five viruses that infect Chlorella Pbi (CVA-1, CVB-1, CVG-1, CVM-1, and CVR-1). The DNAs were hybridized with entire grx gene (237 bp) probes. The blots contain $1,0.5,0.25$, and $0.12 \mu \mathrm{g}$ of DNA, left to right, respectively.

probability tree indicates that the Grx molecules of the Chlorella viruses are closely related, yet display diversity when compared to Chlorella NC64A (the host of PBCV-1, NY-2A and AR158) and other organisms (Figure 6). Sequence alignments conducted for phylogenetic analyses indicate that while the three NC64A Chlorella viruses share the monothiol characteristic as well as the approximate location of the active site (similar to first and second class Grxs), the sequence of the active site of PBCV-1 differs from that of AR158 and NY2A. This is demonstrated in the sharing of a more recent common ancestor between the latter two (Figure 6). FR483 and MT325, viruses that infect Chlorella Pbi, and ATCV-1, which infects Chlorella SAG 3.83, each encode two Grxs which have dithiol active sites and share the same sequence. Prochlorococcus and Synechococcus phage encode molecules that are consistent with the first class Grx. Members of the family Phycodnaviridae belong to the Nucleocytoplasmic Large DNA Viruses (NLDV) group. It is believed 

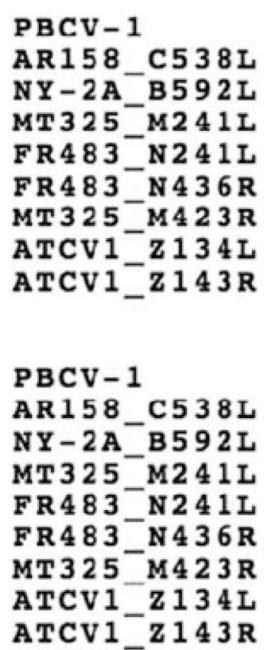
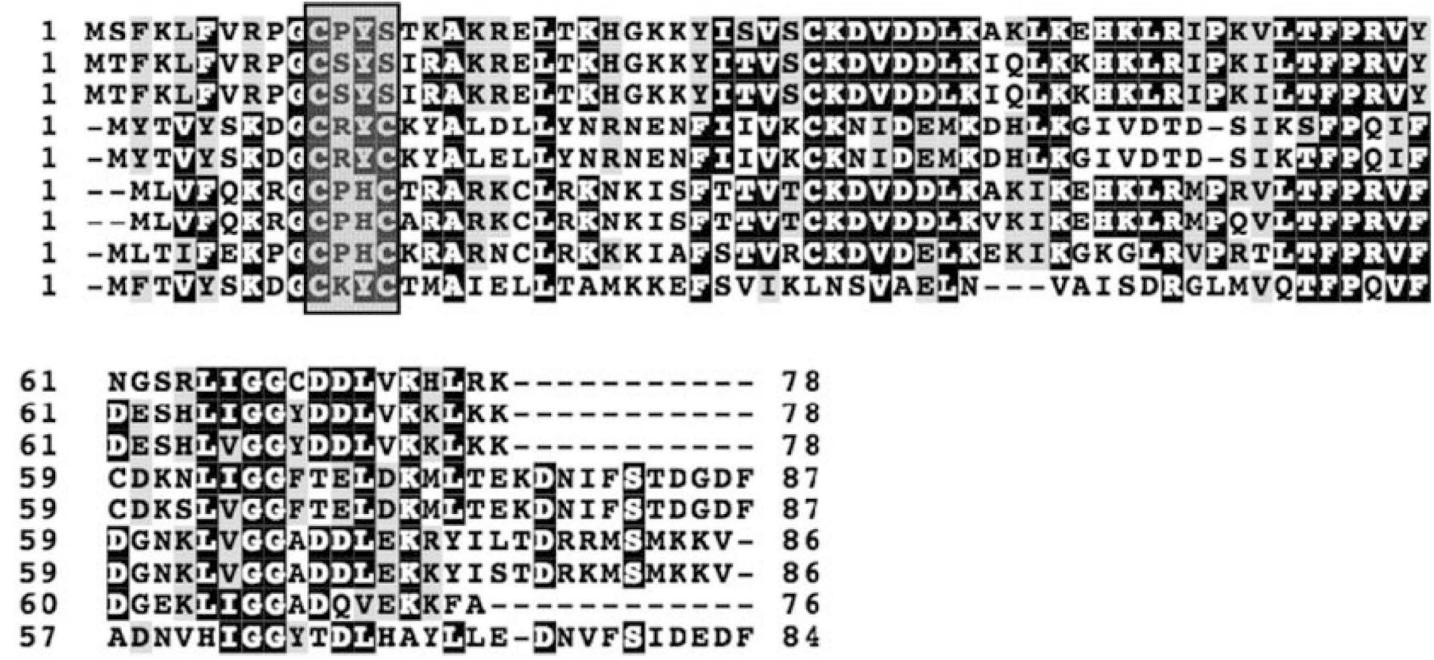

Figure 5. Multiple amino acid sequence alignment of Chlorella virus Grxs similar to PBCV-1 Grx. The gray box indicates the Grx active site.

that members of this group shared a common ancestor 2-3 billion years ago [30-32]. NLDV includes the Pox viruses (i.e. Vaccinia and Variola viruses, shown), Iridoviruses (i.e. Invertebrate iridescent virus 6, shown), African Fever Virus (shown) and Acanthamoeba polyphaga mimivirus. This large DNA virus shares the frequently conserved dithiol, CPYC of these classes, yet the site is more central in location. These variations demonstrate the diversity of the Grx molecule and are supported by the phylogenetic analyses (Figure 6). MUSCLE alignments, Neighbor-Joining (Geneious Tree Builder, Jukes-Cantor Model and Maximum Likelihood (PHYML, Jones-Taylor-Thornton Model) phylogenies support these findings (data not shown) [24].

\section{Discussion}

This study establishes that Chlorella virus PBCV-1, like many large dsDNA viruses, encodes a functional Grx. Sequence analysis indicates that this enzyme is similar to both prokaryotic and eukaryotic Grxs.

There are four classes of Grx [4, 7-11]. The class I, or the classical Grxs are 9-12 kDa in size and they have a dithiol active site located near the N-terminus of the enzyme. This active site typically consists of CPYC. The second class also contains the dithiol CPYC active site near the N-terminus, however, this enzyme is $24 \mathrm{kDa}$ in size. The third class, which is present in yeast, is 9$12 \mathrm{kDa}$ in size, however, they contain a monothiol (CGFS) active site located in the middle of the protein. Finally, the fourth class has only been found in higher plants and typically has a CCXC or CCXS sequence.

PBCV-1 Grx is unusual because it does not easily fit in any of the four classes of Grxs. The PBCV-1 Grx 9-
kDa size excludes it from the second class of Grxs. The CPYS active site near the N-terminus places PBCV-1 Grx in the classical Grxs with an atypical active site. The recently sequenced genome of the host Chlorella NC64A indicates it has a standard class III Grx (Fitzgerald et al. unpublished results).

Classical dithiol Grxs contain a CPYC active site motif, which use both cysteine residues for the reduction of protein disulfides. A previous study mutated the CPYC active site of an E. coli Grx to determine which amino acids were necessary for activity [5]. Mutation in the C-terminus cysteine resulted in a $50 \%$ loss of activity.

In the current study, experiments were performed to determine the effect that mutation of either the cysteine or the serine located in the active site had on its activity. When the enzyme was mutated to the dithiol (CPYC) the specific activity and the $\mathrm{Km}$ were essentially the same but the $V_{\max }$ was 2-fold higher than that of wild type Grx. When the serine in the active site was mutated to an alanine (CPYA), there was no difference in the kinetics compared to the wild type enzyme. The enzyme was completely inactive when the cysteine and the serine were switched (SPYC) or when no cysteines were present in the active site (SPYS).

These results indicate that PBCV-1 Grx requires a cysteine in the $\mathrm{N}$-terminal position of the active site to be active. The amino acid located in the C-terminal position of the active site has little effect on enzyme activity.

Gene $a 4381$ orthologs are probably present in all of the chloroviruses even though some of the virus genomes do not hybridize with the $a 4381$ probe. This supposition is supported by the finding that one or two grx genes exist in all five newly sequenced Chlorella viruses [2729]. However, the lack of hybridization to some virus genomes probably reflects considerable gene divergence 


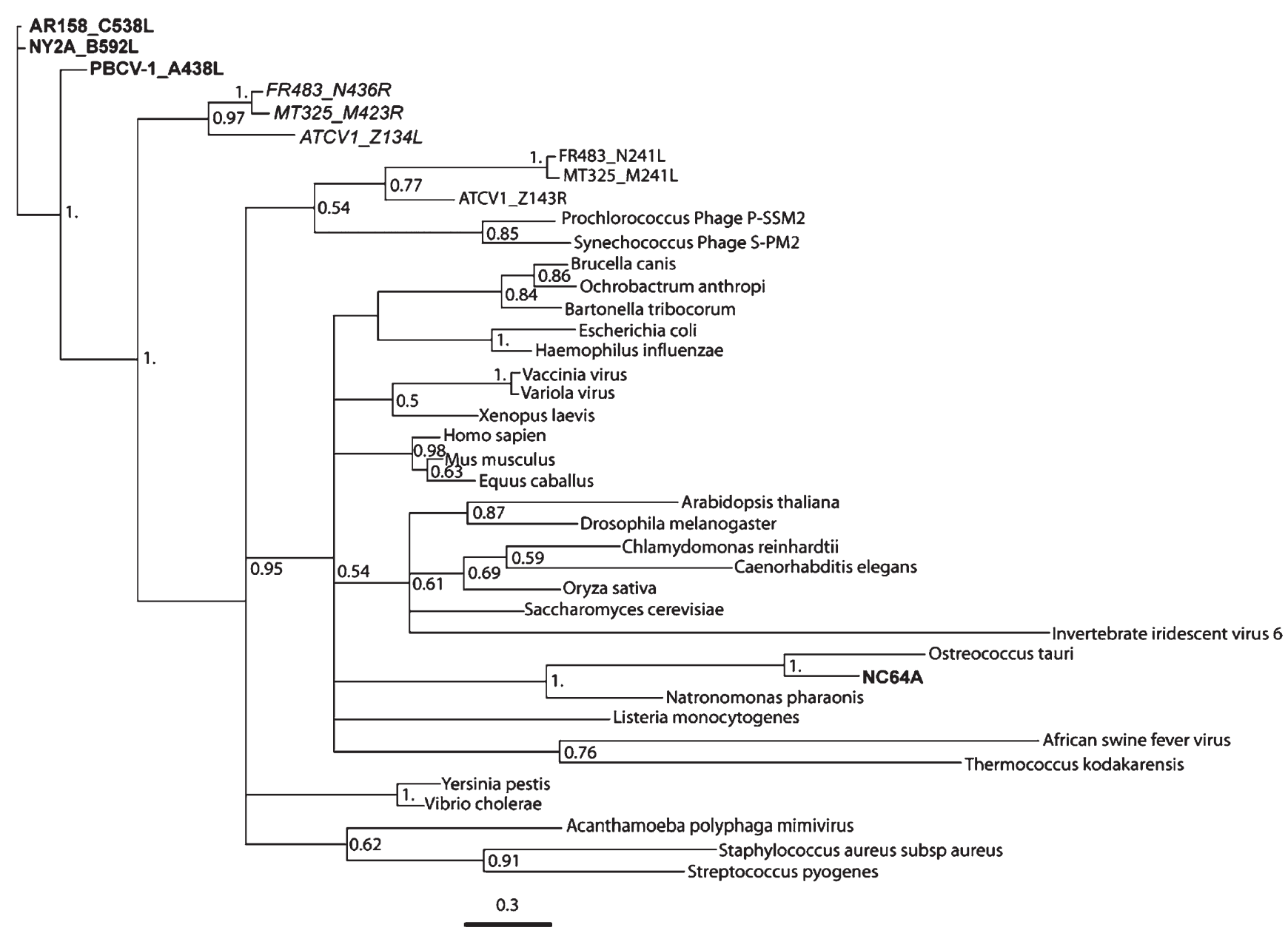

Figure 6. Bayesian inference posterior probability phylogenetic tree of 40 glutaredoxin protein sequences. The phylogenetic tree was constructed using MrBayes, based on a sequence alignment conducted on ClustalX-2.0.10 within Geneious Pro 4.5.5. (Poisson fixed) amino acid rate matrix with gamma rate variation and 4 categories. MCMC parameters were chain length, 1,100,000, 4 heated chains, temperature set at 0.2 . The frequency of subsampling was 200 with burn in length of 100,000). The tree is "unrooted," clade support values of less than 0.50 are not shown. 4951 tree samples were analyzed. Viruses AR158, NY2A and PBCV1 infect Chlorella NC64A (viral Grx homologs and Chlorella NC64A are in bold). Viruses FR483 and MT325 infect Chlorella Pbi and virus ATCV-1 infects Chlorella SAG 3.83 (hosts not shown, viral Grx homologs italicized). The latter three viruses each encode a second Grx, which are also shown.

among these viruses. The phylogenetic analyses support the presence of the Grx molecule as being conserved across all domains of life, sharing similar motifs in some cases, yet at the same time displaying a high degree of diversity. Divergence is evident within the Chlorella viruses and there is some indication that this may be in a host dependent manner. As previously presented, the type virus, PBCV-1, does not display the complete set of characteristics of any of the designated classes, yet its single cell eukaryotic host Chlorella NC64A has a standard class III Grx species.

Grx provides the reducing power to ribonucleotide reductase, a key enzyme for deoxyribonucleotide biosynthesis. The fact that PBCV-1 encodes a functional Grx and its sister enzyme thioredoxin is not unexpected since deoxyribonucleotide biosynthesis occurs extremely fast during its life cycle [33]. In fact, microarray experiments indicate that the PBCV-1 grx gene is expressed as both an early and late gene in the virus life cycle, suggesting its importance to viral replication (Yanai-Balser et al. manuscript in preparation).

Acknowledgments - This investigation was supported in part by Public Health Service grant GM32441 (JLVE) and NIH grant P20RR15635 from the COBRE program of the National Center for Research Resources (JLVE). GL was supported by a Ruth L. Kirschstein National Research Service Award 1 T32 AI060547 from the National Institute of Allergy and Infectious Diseases. 


\section{References}

1. E. Herrero, M. A. de la Torre-Ruiz, Cell. Mol. Life Sci. 64, 1518-1530 (2007)

2. C. H. Lillig, C. Berndt, A. Holmgren, Biochim. Biophys. Acta 1780, 1304-1317 (2008)

3. A. Holmgren, in Advances in Photosynthesis and Respiration, vol. 11 ed. by E. M. Aro, B. Andersson (Springer, Dordrecht, 2001), pp. 321-330

4. A. Holmgren, F. Aslund, Methods Enzymol. 252, 283-292 (1995)

5. J. H. Bushweller, F. Aslund, K. Wuthrich, A. Holmgren, Biochemistry 31, 9288-9293 (1992)

6. E. Eckers, M. Bien, V. Stroobant, J. M. Herrmann, M. Deponte, Biochemistry 48, 1410-1423 (2009)

7. A. Vlamis-Gardikas, A. Holmgren, Methods Enzymol. 347, 286-296 (2002)

8. E. Herrero, J. Ros, J. Tamarit, G. Belli, Photosynth. Res. 89, 127-140 (2006)

9. N. Rouhier, E. Gelhaye, J. P. Jacquot, Cell. Mol. Life Sci. 61, 1266-1277 (2004)

10. L. Michelet, M. Zaffagnini, V. Massot, E. Keryer, H. Vanacker, M. Miginiac-Maslow, E. Issakidis-Bourguet, S. D. Lemaire, Photosynth. Res. 89, 225-245 (2006)

11. S. D. Lemaire, Photosynth. Res. 79, 305-318 (2004)

12. A. Vlamis-Gardikas, F. Aslund, G. Spyrou, T. Bergman, A. Holmgren, J. Biol. Chem. 272, 11236-11243 (1997)

13. J. L. Martin, Structure 3, 245-250 (1995)

14. J. H. Bushweller, M. Billeter, A. Holmgren, K. Wuthrich, J. Mol. Biol. 235, 1585-1597 (1994)

15. G. F. Kutish, Y. Li, Z. Lu, M. Furuta, D. L. Rock, J. L. Van Etten, Virology 223, 303-317 (1996)

16. J. L. Van Etten, R. H. Meints, D. E. Burbank, D. Kuczmarski, D. A. Cuppels, L. C. Lane, Virology 113, 704-711 (1981)

17. J. L. Van Etten, D. E. Burbank, Y. Xia, R. H. Meints, Virology 126, 117-125 (1983)
18. J. Sambrook, E. F. Fritsch, T. Maniatis, Molecular Cloning: A Laboratory Manual (Cold Spring Harbor Laboratory Press, Cold Springs Harbor, NY, 1989)

19. O. H. Lowry, N. J. Rosebrough, A. L. Farr, R. J. Randall, J. Biol. Chem. 193, 265-275 (1951)

20. J. J. Mieyal, D. W. Starke, S. A. Gravina, B. A. Hocevar, Biochemistry 30, 8883-8891 (1991)

21. J. J. Mieyal, D. W. Starke, S. A. Gravina, C. Dothey, J. S. Chung, Biochemistry 30, 6088-6097 (1991)

22. N. Raghavachari, M. F. Lou, Exp. Eye Res. 63, 433-441 (1996)

23. M. V. Graves, C. T. Bernadt, R. Cerny, J. L. Van Etten, IU 285, 332-345 (2001)

24. A. J. Drummond, B. Ashton, M. Cheung, J. Heled, M. Kearse, R. Moir, S. Stones-Havas, A. Wilson, Geneious Pro v455, 2008; available from http:/ / wwwgeneious.com

25. Wisconsin Package. Accelrys Inc., San Diego, CA, 2001

26. J. L. Van Etten, R. H. Meints, Annu. Rev. Microbiol. 53, 447494 (1999)

27. L. A. Fitzgerald, M. V. Graves, X. Li, J. Hartigan, A. J. Pfitzner, E. Hoffart, J. L. Van Etten, Virology 362, 350-361 (2007)

28. L. A. Fitzgerald, M. V. Graves, X. Li, T. Feldblyum, W. C. Nierman, J. L. Van Etten, Virology 358, 472-484 (2007)

29. L. A. Fitzgerald, M. V. Graves, X. Li, T. Feldblyum, J. Hartigan, J. L. Van Etten, Virology 358, 459-471 (2007)

30. L. M. Iyer, L. Aravind, E. V. Koonin, J. Virol. 75, 11720 11734 (2001)

31. L. M. Iyer, S. Balaji, E. V. Koonin, L. Aravind, Virus Res. 117, 156-184 (2006)

32. D. Raoult, S. Audic, C. Robert, C. Abergel, P. Renesto, H. Ogata, B. La Scola, M. Suzan, J. M. Claverie, Science 306, 1344-1350 (2004)

33. J. L. Van Etten, D. E. Burbank, J. Joshi, R. H. Meints, Virology 134, 443-449 (1984) 